\title{
Puerarin in inducing apoptosis of bladder cancer cells through inhibiting SIRT1/p53 pathway
}

\author{
GUOMEI YE ${ }^{1}$, SHIFENG KAN ${ }^{2}$, JIANFENG CHEN ${ }^{3}$ and XIN LU ${ }^{4}$ \\ ${ }^{1}$ Department of Urinary Surgery, The Second Hospital of Shandong University, Jinan, Shandong 250000; \\ ${ }^{2}$ Department of Clinical Laboratory, Qilu Hospital of Shandong University, Jinan, Shandong 250012; \\ ${ }^{3}$ Blood Center of Shandong Province and ${ }^{4}$ Department of Blood Transfusion, The Second Hospital \\ of Shandong University, Jinan, Shandong 250000, P.R. China
}

Received April 6, 2018; Accepted September 24, 2018

DOI: $10.3892 / \mathrm{ol} .2018 .9600$

\begin{abstract}
Regulatory effect of puerarin on bladder cancer T24-cell apoptosis and its possible mechanism were investigated. The experimental subjects were divided into the experimental group, the control group and the blank control group, and the cell inhibition rates after treatment were detected, respectively. Then, subjects were further divided into the control group, the puerarin group (treated with puerarin), the agonist group [treated with silent information regulator 1 (SIRT1) agonist SRT1720], the inhibitor group (treated with SIRT1 inhibitor EX527) and the combination group (treated with SRT1720, and then with puerarin). Apoptosis in each group was detected via flow cytometry, and the expression of apoptosis-related proteins, and SIRT1 and p53 proteins in each group was detected via western blotting. Moreover, the expression of SIRT1 and p53 messenger ribonucleic acid (mRNA) was detected via reverse transcription-quantitative polymerase chain reaction (RT-qPCR). The inhibition rate of bladder cancer T24 cells was significantly increased after treatment with puerarin at different concentrations. Compared with those in the normal control group, the inhibition rates at 24,48 and $72 \mathrm{~h}$ after treatment with puerarin were significantly increased $(\mathrm{p}<0.05)$. Compared with those in the control group, the apoptosis rate of T24 cells was remarkably increased after treatment with different doses of puerarin or EX527, and the expression level of apoptosis-related protein Bcl-2-associated $\mathrm{X}$ protein (Bax) was also significantly increased, but the expression level of B-cell lymphoma 2 (Bcl-2) was decreased, and both the protein and mRNA expression levels of SIRT1 and p53 also significantly declined. Compared with those in the puerarin group, the apoptosis rate in the combination group
\end{abstract}

Correspondence to: Dr Xin Lu, Department of Blood Transfusion, The Second Hospital of Shandong University, 247 Beiyuan Street, Tianqiao, Jinan, Shandong 250000, P.R. China

E-mail: utx92t@163.com

Key words: puerarin, bladder cancer, silent information regulator 1, p53, apoptosis was decreased, and the expression level of apoptosis-related protein Bax was also significantly decreased, but the expression level of Bcl-2 was increased, and SIRT1 and p53 protein expression levels were also remarkably increased. Puerarin can inhibit the proliferation of bladder cancer T24 cells and induce apoptosis, and the possible mechanism is related to the inhibition of SIRT1/p53 signaling pathway.

\section{Introduction}

Bladder cancer is one of the most common malignant tumors in urinary surgery, and the incidence rate shows a continuously increasing trend in the world (1). In China, the morbidity and mortality rates of bladder cancer rank first in malignant tumors of the male reproductive system (2). Due to the lack of early diagnostic means, lymph node metastasis has often occurred at the diagnosis of disease. At present, surgical treatment is mainly adopted for bladder cancer in clinical practice, but such a method is more traumatic to patients. As a result, the quality of life is not high, and tumor cells are prone to metastasis (3). In addition to surgery, conventional basic chemotherapy drugs, such as cisplatin, are also one of the clinical treatment methods, which can achieve satisfactory effects within a short period. Due to the longer cycle of chemotherapy, however, the patient's body is prone to drug tolerance, and bone marrow suppression and adverse reactions in the nervous system occur easily (4). Therefore, searching for an effective and safe drug is currently a main direction in the clinical treatment of bladder cancer.

Puerarin is an isoflavone substance extracted from plants such as Pueraria thomsonii, and plays an important role in tumor apoptosis, proliferation and immunity (5). Studies have shown that puerarin can induce apoptosis of human cervical cancer cells through inhibiting Wnt/ $\beta$-catenin signaling pathway (6). Numerous studies have confirmed that puerarin has a significant inhibitory effect on various malignant tumor cells, including bladder cancer cells (7). However, there is little research on puerarin in regulating bladder cancer cell proliferation and apoptosis, and its possible molecular mechanism remains unclear. Silent information regulator 1 (SIRT1) is one of the members of the mammalian sirtuin family with the main role of regulating the substance metabolism and lifespan (8). According to studies, SIRT1 can deacetylate 
the lysine residue at position 382 of the tumor suppressor protein p53, thereby reducing p53 activity and allowing cells to bypass p53-mediated apoptosis and continue to survive (9). However, little is known about the role of SIRT1 in bladder cancer cells. In this study, the regulatory effects of puerarin on apoptosis-related proteins, SIRT1 and p53 in human bladder cancer T24 cells were observed, and the effect of puerarin on apoptosis of bladder cancer cells and its molecular mechanism were preliminarily studied.

\section{Materials and methods}

\section{Materials}

Cell lines. Bladder cancer T24 cell lines (cat. no. FS-0139) were purchased from the Cell Bank of the Peking Union Medical College.

Main reagents. High-glucose Dulbecco's modified Eagle's medium (DMEM), fetal bovine serum (FBS) and trypsin were purchased from Dow Corning (Midland, MI, USA). Methyl thiazolyltetrazolium(MTT) kit and Annexin V cell apoptosis kit were purchased from Nanjing KeyGen Biotech Co., Ltd. (Nanjing, China). M-MuLV Reverse Transcriptase kit and SYBR-Green I real-time fluorescence quantitative polymerase chain reaction (PCR) kit were purchased from Thermo Fisher Scientific, Inc. (Waltham, MA, USA). SIRT1 agonist SRT1720 and inhibitor EX527 were from Sigma-Aldrich (Sigma-Aldrich: Merck KGaA, St. Louis, MO, USA) [dissolved at $1 \mathrm{mmol} / \mathrm{l}$ with dimethylsulfoxide (DMSO), and stored at $-20^{\circ} \mathrm{C}$ in the dark]. Primary mouse anti-human SIRT1, p53, B-cell lymphoma 2 (Bcl-2), Bcl-2-associated X protein (Bax) and $\beta$-actin monoclonal antibodies, and horseradish peroxidase-labeled secondary goat anti-mouse polyclonal antibody (cat. nos. sc-135792, sc-47698, sc-509,sc-20067, sc-58673 and sc-2005, were purchased from Santa Cruz Biotechnology, Inc. (Santa Cruz, CA, USA). SIRT1, p53 and glyceraldehyde-3-phosphate dehydrogenase (GAPDH) gene primer sequences were synthesized by Nanjing KeyGen Biotech Co., Ltd.

The study was approved by the Ethics Committee of the Second Hospital of Shandong University (Jinan, China). Informed consents were signed by the patients and/or guardians.

\section{Main methods}

Cell culture and grouping. Human bladder cancer T24 cell lines were cultured in high-glucose DMEM containing 10\% FBS. After meeting the experimental conditions, cells in the logarithmic growth phase were taken for experiments. After centrifugation at $860 \mathrm{x} \mathrm{g}$ for $5 \mathrm{~min}$ at $4^{\circ} \mathrm{C}$, cell sediment was taken, and cells were resuspended and inoculated into culture plates in different specifications according to the experimental requirements. After cells fully adhered to the wall, puerarin in a given concentration (0-200 $\mu \mathrm{mol} / \mathrm{l})$, SIRT1 agonist SRT1720 $(1 \mu \mathrm{mol} / \mathrm{l})$ or SIRT1 inhibitor EX527 $(1 \mu \mathrm{mol} / \mathrm{l})$ was added for routine culture under $5 \% \mathrm{CO}_{2}$ at $37^{\circ} \mathrm{C}$ for a predetermined time, followed by subsequent experiment.

Detection of T24-cell proliferation via MTT assay. Experimental subjects were divided into blank control, control and experimental groups. Human bladder cancer T24 cells were inoculated into a 96-well plate, and the cell density was controlled at $5 \times 10^{3}$ cells/well, and six repeated wells were set in each group. After cells adhered to the wall, $1 \%$ bovine serum albumin containing no puerarin (control group) and containing 20,50, 100 and $200 \mu \mathrm{mol} / 1$ puerarin (experimental groups) were added, respectively, for incubation in an incubator with $5 \% \mathrm{CO}_{2}$ at $37^{\circ} \mathrm{C}$ for 24,48 and $72 \mathrm{~h}$. Then, $200 \mu 1 \mathrm{DMSO}$ was added into each well and vibrated at a low speed on a shaking table for $10 \mathrm{~min}$ to completely dissolve the crystals. The protocol was repeated 3 times. The absorbance value of each well was measured at a wavelength of $490 \mathrm{~nm}$ by using a microplate reader (Bio-Rad 680; Bio-Rad Laboratories, Inc., Hercules, CA, USA). The blank control group (without cells and puerarin) was used for zero setting. Cell inhibition rate $=1$ - (absorbance value experimental group - absorbance value blank $_{\text {b }}$ control group $) /($ absorbance value control group - absorbance value blank control group) $\mathrm{x} 100 \%$.

Detection of T24-cell apoptosis via flow cytometry. T24 cells in the logarithmic growth phase were inoculated into the petri dish, and treated with puerarin $(100 \mu \mathrm{mol} / \mathrm{l})$, SRT1720 $(1 \mu \mathrm{mol} / \mathrm{l})$ and EX527 $(1 \mu \mathrm{mol} / \mathrm{l})$ for $24 \mathrm{~h}$ according to the experimental requirements. After digestion with trypsin, adherent cells were collected, counted and washed with phosphate-buffered saline (PBS) twice. Then, the cells in each group were resuspended in $500 \mu \mathrm{l}$ binding buffer, and $5 \mu \mathrm{l}$ Annexin $\mathrm{V}$ and $5 \mu \mathrm{l}$ propidium iodide were added, followed by incubation in the dark at room temperature for $15 \mathrm{~min}$. Finally, the apoptosis rate was detected via flow cytometry (Thermo Fisher Scientific, Inc.).

Detection of protein expression levels via western blotting. T24 cells in the logarithmic growth phase were inoculated into the petri dish, and treated with puerarin $(100 \mu \mathrm{mol} / \mathrm{l})$, SRT1720 $(1 \mu \mathrm{mol} / \mathrm{l})$ and EX527 $(1 \mu \mathrm{mol} / \mathrm{l})$ for $24 \mathrm{~h}$ according to the experimental requirements. Cells were added with the radioimmunoprecipitation assay (RIPA) lysis buffer at $4^{\circ} \mathrm{C}$ and incubated for $30 \mathrm{~min}$. The total protein was extracted, and the protein concentration was detected by using the bicinchoninic acid (BCA) kit, and the protein curve was drawn. Then, $60 \mu \mathrm{g}$ total protein was taken for sample spotting, and isolated via $10 \%$ sodium dodecyl sulfate-polyacrylamide gel electrophoresis (SDS-PAGE), after which the protein was transferred onto a polyvinylidene fluoride (PVDF) membrane under $100 \mathrm{~V}$ for 150 min, blocked with 5\% skim milk powder at room temperature for $1 \mathrm{~h}$, and incubated with primary antibody (1:500) at $4^{\circ} \mathrm{C}$ overnight, with $\beta$-actin (1:600) as the internal reference. After being washed with PBS, the protein was added with the secondary antibody $(1: 800)$ for incubation at $37^{\circ} \mathrm{C}$ for $2 \mathrm{~h}$. Finally, the band image was collected after electrochemiluminescence development (Bio-Rad Laboratories, Inc.) and the optical density value of protein band was measured by using the gel imaging analysis system (Bio-Rad Laboratories, Inc.). The gray value of the target protein band was scanned by Quantity One software, and the expression intensity of each group was indicated by the ratio of the gray value of the target protein band to $\beta$-actin band.

Detection of messenger ribonucleic acid (mRNA) expression via reverse transcription-quantitative polymerase chain reaction ( $R T-q P C R)$. T24 cells in the logarithmic growth phase were taken and treated with puerarin $(100 \mu \mathrm{mol} / \mathrm{l})$, SRT1720 $(1 \mu \mathrm{mol} / \mathrm{l})$ and EX527 $(1 \mu \mathrm{mol} / \mathrm{l})$ for $24 \mathrm{~h}$ according to the experimental requirements. RNA was extracted from cells by using TRIzol reagent via one-step method, reverse transcribed into complementary deoxyribonucleic acid (cDNA) and then amplified into DNA in strict accordance with the 


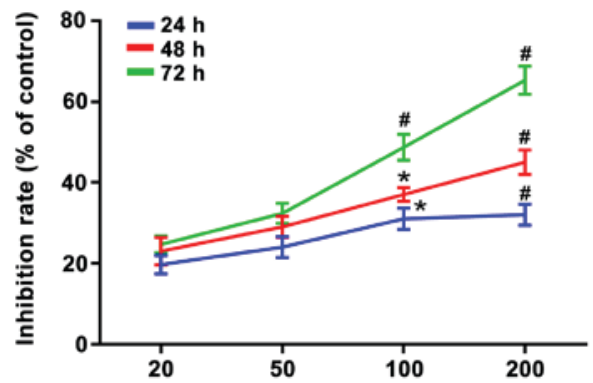

Figure 1. Inhibitory effect of puerarin on proliferation of bladder cancer T24 cells. The cell inhibition rates under 100 and $200 \mu \mathrm{g} / \mathrm{ml}$ puerarin at 24 , 48 and $72 \mathrm{~h}$ were higher compared with those in the normal control group $(\mathrm{p}<0.05) .{ }^{*} \mathrm{P}<0.05$ and ${ }^{\#} \mathrm{P}<0.01$ vs. the normal control group.

manufacturer's instructions of the reverse transcription and SYBR-Green I real-time fluorescence quantitative polymerase chain reaction (PCR) kit, followed by quantitative analysis of the target gene. Primer sequences of SIRT1: forward, 5'-CTGCCTGGATCCCCTTAGTTTTG-3' and reverse, 5'-GGGCCTGTTGCTCTCCTCATTAA-3'. Primer sequences of p53: forward, 5'-CCGGCGCACAGAGG AAGAGA-3' and reverse, 5'-TGGGGAGAGGAGCTGGTGT TGT-3'. Primer sequences of GAPDH as an internal reference: forward, 5'-CATGGGGTGTGAACCATGAGA-3' and reverse, 5'-GTCTTCTGGGTGGCAGTGAT-3'. The $2^{-\Delta \Delta C q}$ method was used for quantification (10). The thermocycling conditions were as follows: Predenaturation at $95^{\circ} \mathrm{C}$ for $10 \mathrm{~min}$, then denaturation at $95^{\circ} \mathrm{C}$ for $30 \mathrm{sec}$, annealing at $50^{\circ} \mathrm{C}$ for $30 \mathrm{sec}$, at $95^{\circ} \mathrm{C}$, extension at $70^{\circ} \mathrm{C}$ for $1 \mathrm{~min}, 40$ cycles, and finally extending $10 \mathrm{~min}$ at $70{ }^{\circ} \mathrm{C}$. The experiment was repeated 3 times.

Statistical analysis. Statistical Product and Service Solutions (SPSS) 22.0 software (IBM Corp., Armonk, NY, USA) was used for data entry, and data were collected and statistically analyzed. t-test was used for the comparison of measurement data between the two groups, and one-way analysis of variance was used for the data comparison among groups and the post hoc test was the Least Significant Difference test. $\mathrm{P}<0.05$ indicated that the difference was statistically significant.

\section{Results}

Inhibitory effect of puerarin on proliferation of bladder cancer T24 cells (Fig. 1). Results of MTT assay revealed that the inhibition rate of bladder cancer T24 cells was significantly increased after treatment with puerarin at different concentrations $(0,20,50,100$ and $200 \mu \mathrm{g} / \mathrm{ml})$, and it was elevated with the increase of treatment time and dose, displaying an obvious dose-effect relationship. A total of 20 and $50 \mu \mathrm{g} / \mathrm{ml}$ puerarin could inhibit the proliferation of T24 cells, and there was no statistically significant difference compared with the normal control group ( $\mathrm{p}>0.05)$. The cell inhibition rates under $100 \mu \mathrm{g} / \mathrm{ml}$ puerarin at 24,48 and $72 \mathrm{~h}$ had statistically significant differences compared with those in the normal control group ( $\mathrm{p}<0.05)$. Besides, there were also statistically significant differences in the cell inhibition rates under $200 \mu \mathrm{g} / \mathrm{ml}$ puerarin at 24, 48 and $72 \mathrm{~h}$ compared with those in the normal control group $(\mathrm{p}<0.01)$.
Puerarin induces apoptosis of bladder cancer T24 cells. Results of flow cytometry manifested that compared with control group, $100 \mu \mathrm{g} / \mathrm{ml}$ puerarin could significantly increase the proportion of apoptosis in bladder cancer T24 cells $(p<0.05)$. However, compared with that in the puerarin group, the proportion of apoptotic T24 cells was significantly decreased after pre-treatment with SIRT1 agonist SRT1720 for $1 \mathrm{~h}$ and then treatment with $100 \mu \mathrm{g} / \mathrm{ml}$ puerarin for $24 \mathrm{~h}$ $(\mathrm{p}<0.05)$. Compared with the control group, the administration of SRT1720 alone did not increase the proportion of apoptotic T24 cells, and the difference was not statistically significant ( $>0.05$ ). However, the administration of SIRT1 inhibitor EX527 alone for $24 \mathrm{~h}$ could simulate the effect of puerarin to induce T24-cell apoptosis ( $\mathrm{p}<0.05$ ) (Fig. 2A and B). According to the results of western blotting, compared with the control group, $100 \mu \mathrm{g} / \mathrm{ml}$ puerarin could obviously increase the Bax protein expression and decrease the $\mathrm{Bcl}-2$ protein expression in T24 cells, so the Bax/Bcl-2 ratio was increased significantly $(\mathrm{p}<0.05)$. Moreover, compared with those in the puerarin group, expression of the Bax and Bcl-2 protein in T24 cells were reversed, and the $\mathrm{Bax} / \mathrm{Bcl}-2$ ratio was decreased after administration of SIRT1 agonist SRT1720 ( $p<0.05)$. Compared with those in the control group, the Bax protein expression was not increased and the Bcl-2 protein expression was not decreased after administration of SRT1720 alone, and there were no statistically significant differences ( $\mathrm{p}>0.05)$. However, the administration of SIRT1 inhibitor EX527 alone for $24 \mathrm{~h}$ could simulate the effect of puerarin to increase the Bax protein expression and $\mathrm{Bax} / \mathrm{Bcl}-2$ ratio and decrease the $\mathrm{Bcl}-2$ protein expression $(\mathrm{p}<0.05)$ (Fig. 2C-F).

Effect of puerarin on SIRT1/p53 pathway in bladder cancer T24 cells. Results of western blotting manifested that compared with control group, $100 \mu \mathrm{g} / \mathrm{ml}$ puerarin could remarkably reduce expression of SIRT1 and p53 protein in T24 cells $(\mathrm{p}<0.05)$. Compared with those in the puerarin group, expression of SIRT1 and p53 protein in T24 cells could be reversed after administration of SIRT1 agonist SRT1720. The administration of SRT1720 alone could increase the SIRT1 and p53 protein expression compared with the control group $(\mathrm{p}<0.05)$. However, the administration of SIRT1 inhibitor EX5272 alone for $24 \mathrm{~h}$ simulated the effect of puerarin to reduce the SIRT1 and $\mathrm{p} 53$ protein in T24 cells $(\mathrm{p}<0.05)$ (Fig. 3A-C). According to the results of RT-qPCR, $100 \mu \mathrm{g} / \mathrm{ml}$ puerarin could obviously reduce the expression of SIRT1 and p53 mRNA in T24 cells compared with the control group $(\mathrm{p}<0.05)$. Compared with those in the puerarin group, the expression of SIRT1 and p53 mRNA in T24 cells was reversed after administration of SIRT1 agonist SRT1720. The administration of SRT1720 alone could increase the SIRT1 and p53 mRNA expression compared with the control group $(\mathrm{p}<0.05)$. However, the administration of SIRT1 inhibitor EX5272 alone for $24 \mathrm{~h}$ could simulate the effect of puerarin to reduce the expression of SIRT1 and p53 mRNA in T24 cells ( $p<0.05)$ (Fig. 3D and E).

\section{Discussion}

Bladder cancer is one of the frequently occurring tumors in men, as well as an important cause of cancer death in men. Studies have demonstrated that heavy smoking and drinking 
A

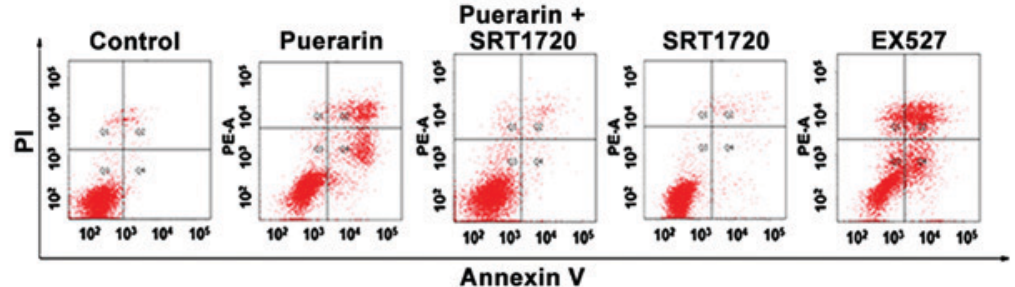

B

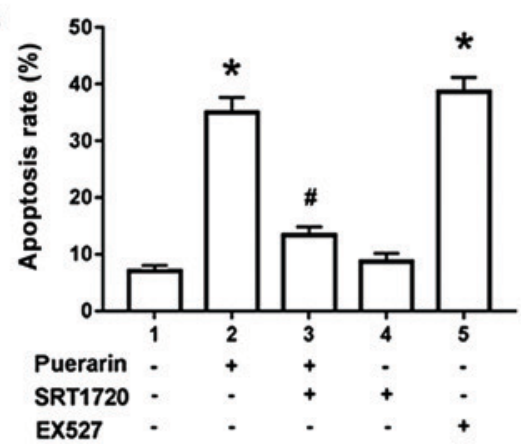

D

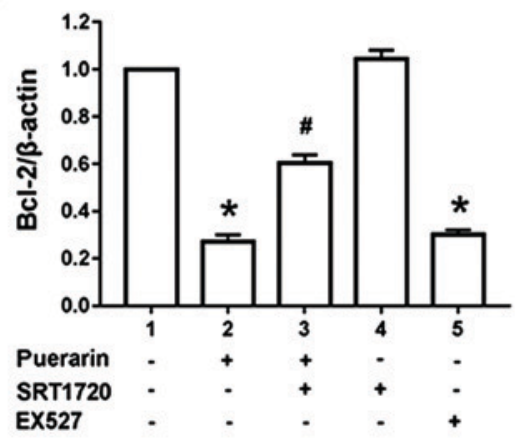

$\mathbf{F}$

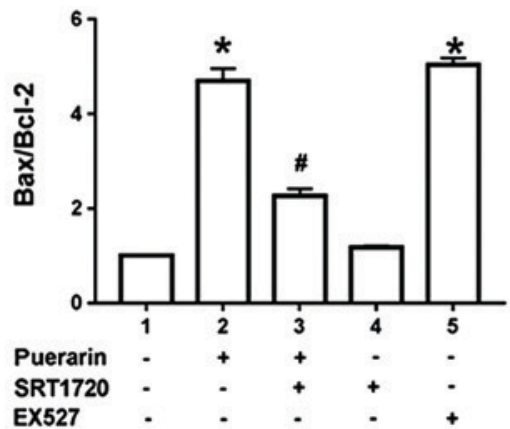

C

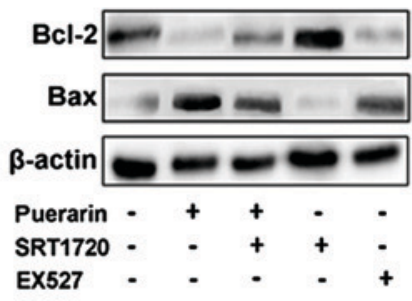

E

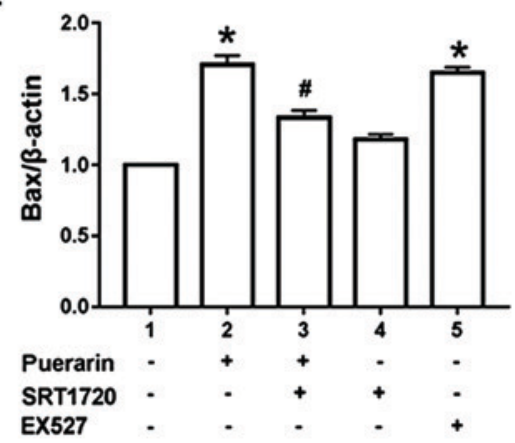

Figure 2. Puerarin induces apoptosis of bladder cancer T24 cells. (A and B) Flow cytometry was conducted to determine apoptosis of T24 cells treated with puerarin, SRT1720, EX527 and puerarin combined with SRT1720. (C-E) The protein levels of Bax, Bcl-2 were determined by western blotting in T24 cells treated with puerarin, SRT1720, EX527 and puerarin combined with SRT1720. (F) The Bax/Bcl-2 ratio in T24 cells treated with puerarin, SRT1720, EX527 and puerarin combined with SRT1720. ${ }^{*} \mathrm{P}<0.05$ vs. control group, ${ }^{\#} \mathrm{P}<0.01$ vs. puerarin group. Bax, Bcl-2-associated X protein; Bcl-2, B-cell lymphoma 2 .

will significantly increase the onset risk of bladder cancer, which are not conducive to the prognosis and improvement of life quality of patients (11). However, due to the high recurrence and metastasis rates of bladder cancer, its clinical treatment is often restricted, and there is still lack of reliable and effective treatment means. Therefore, it is of great importance to find a new treatment method.

There is considerable research showing that traditional Chinese medicine can play a regulatory role in disease at a macro-level, and possesses excellent curative effects on delaying, controlling and preventing the recurrence of disease (12). Puerarin is an isoflavone substance extracted from plants such as Pueraria thomsonii. Numerous studies have revealed that puerarin significantly inhibits the proliferation of a variety of breast cancer cells in a time- and dose-dependent manner $(13,14)$. Besides, puerarin can induce apoptosis through the classic caspase apoptosis pathway, and arrest cells in the G2/M phase (15). Results of this study manifested that the proliferation capacity of bladder cancer T24 cells remarkably declined after treatment with puerarin at different concentrations $(0,20,50,100$ and $200 \mu \mathrm{g} / \mathrm{ml})$ in a time- and dose-dependent manner, which were consistent with the above views.

Blocked apoptosis is one of the causes of the infinite proliferation of tumor cells. Bcl-2 family genes and p53 genes are all important in regulating apoptosis. Bcl-2 and Bax, as the two 
A

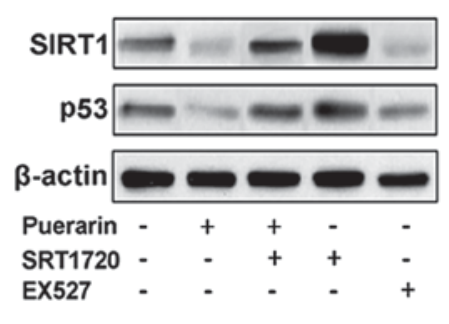

C

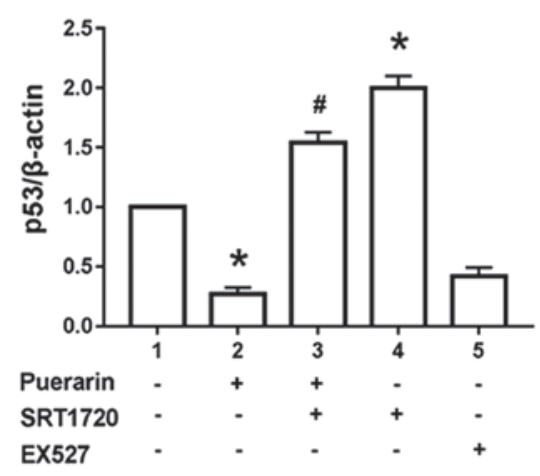

E

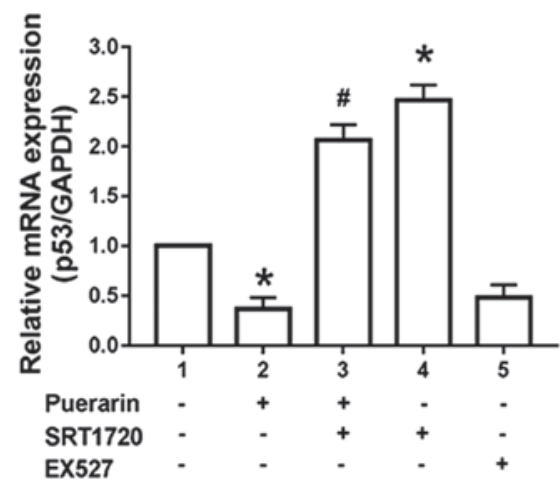

B

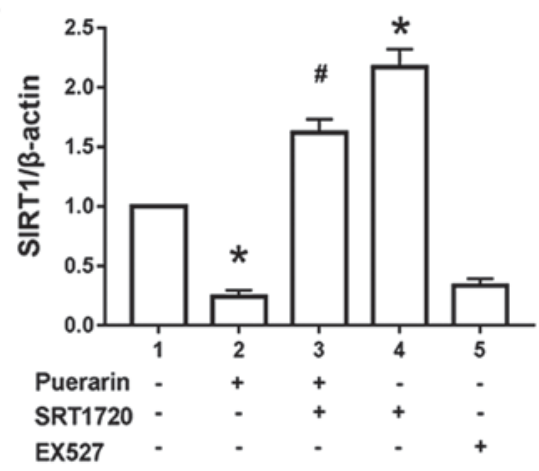

D

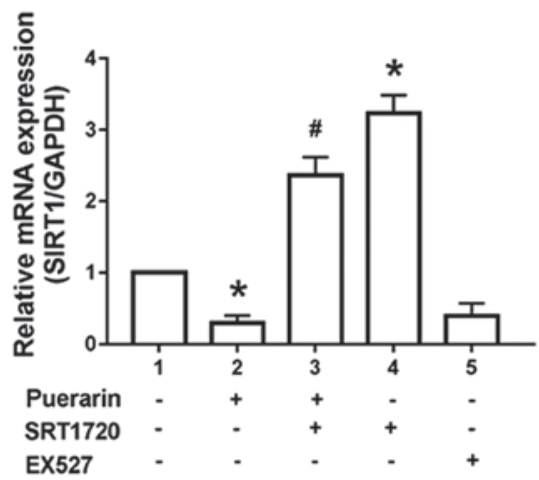

Figure 3. Effect of puerarin on SIRT1/p53 pathway in bladder cancer T24 cells. (A-C) The protein levels of SIRT1, and p53 were determined by western blotting in T24 cells treated with puerarin, SRT1720, EX527 and puerarin combined with SRT1720. (D and E) The mRNA expression of SIRT1 and p53 in T24 cells treated with puerarin, SRT1720, EX527 and puerarin combined with SRT1720. ${ }^{*} \mathrm{P}<0.05$ vs. control group, ${ }^{\sharp} \mathrm{P}<0.01$ vs. puerarin group. SIRT1, silent information regulator 1; mRNA, messenger ribonucleic acid.

most representative genes in the Bcl-2 family, exert effects of inhibiting and promoting apoptosis, respectively. When Bcl-2 is relatively predominant in cells, Bcl-2 will form a heterodimer with Bax, thus inhibiting apoptosis. However, when Bax is predominant in cells, Bax itself will form the homodimer, thus promoting apoptosis $(16,17)$. Therefore, the $\mathrm{Bax} / \mathrm{Bcl}-2$ ratio has important significance for the occurrence and degree of apoptosis. In this study, it was found that $100 \mu \mathrm{g} / \mathrm{ml}$ puerarin could significantly inhibit the proliferation of bladder cancer T24cells, increase the Bax protein expression, and reduce the $\mathrm{Bcl}-2$ protein expression, so the $\mathrm{Bax} / \mathrm{Bcl}-2$ ratio was obviously increased, thereby inducing apoptosis. After administration of SIRT1 agonist SRT1720, the expression of Bax and Bcl-2 protein in T24 cells was reversed, and the Bax/Bcl- 2 ratio was decreased. Besides, the administration of SIRT1 inhibitor EX5272 alone for $24 \mathrm{~h}$ simulated the effect of puerarin to increase the Bax protein expression and the $\mathrm{Bax} / \mathrm{Bcl}-2$ ratio, and decrease the $\mathrm{Bcl}-2$ protein expression, suggesting that puerarin can be used as a novel drug in the treatment of bladder cancer. However, the specific mechanism of puerarin in inhibiting proliferation and inducing apoptosis of bladder cancer cells has not been clarified yet, and it is pending further study.

In recent years, the major role of SIRT1 gene in the occurrence and development of tumors has attracted extensive attention. SIRT1 is an important member of the nicotinamide $\left(\mathrm{NAD}^{+}\right)$-dependent class III histone deacetylase sirtuin family (18). Previous studies found that SIRT1 plays a crucial role in regulating the senescence and substance metabolism of tumor cells (19). Some studies have manifested that the low expression of SIRT1 can induce apoptosis of ovarian cancer cells $(20,21)$, but little is known about SIRT1 in bladder cancer cells. In addition, studies have shown that 
SIRT1 can downregulate the p53 expression through inhibiting acetylation of $\mathrm{p} 53$ protein, thus promoting cell growth (22). In this study, it was found that SIRT1 and p53 protein and mRNA expression in bladder cancer T24 cells could be obviously reduced by $100 \mu \mathrm{g} / \mathrm{ml}$ puerarin, but they could be significantly increased after pre-treatment of T24 cells with SRT1720 for $1 \mathrm{~h}$. Administration of EX527 alone in the treatment of T24 cells could stimulate the effect of puerarin to reduce expression of SIRT1 and p53 protein and mRNA. Therefore, puerarin may induce apoptosis of bladder cancer cells via inhibiting SIRT1/p53 pathway, but its specific regulatory mechanism remains unclear.

In conclusion, this experiment suggested that puerarin can inhibit proliferation and induce apoptosis of bladder cancer T24 cells, and proved that SIRT1/p53 signaling pathway is involved in the pathological process of apoptosis of human bladder cancer T24 cells, laying a foundation for the application of puerarin in prevention and treatment of bladder cancer.

\section{Acknowledgements}

Not applicable.

\section{Funding}

No funding was received.

\section{Availability of data and materials}

The datasets used and/or analyzed during the present study are available from the corresponding author on reasonable request.

\section{Authors' contributions}

GY designed the study and drafted the manuscript. SK collected and analyzed the data. JC performed RT-qPCR. XL was responsible for western blotting. All authors have read and approved the final manuscript.

\section{Ethics approval and consent to participate}

The study was approved by the Ethics Committee of the Second Hospital of Shandong University (Jinan, China). Informed consents were signed by the patients and/or guardians.

\section{Patient consent for publication}

Not applicable.

\section{Competing interests}

The authors declare that they have no competing interests.

\section{References}

1. Mowlds DS, Foster CE and Ichii H: Invasive squamous cell bladder cancer of the ureterovesical junction in a renal transplant patient: A case report. J Surg Case Rep 2017: rjx066, 2017.

2. Wood DP: Re: Current clinical practice gaps in the treatment of intermediate- and high-risk non-muscle-invasive bladder cancer (NMIBC) with emphasis on the use of Bacillus Calmette-Guérin (BCG): results of an international individual patient data survey (IPDS). J Urol 191: 1731, 2014.
3. Zahoor H, Elson P, Stephenson A, Haber GP, Kaouk J, Fergany A, Lee B, Koshkin V, Ornstein M, Gilligan T, et al: Patient characteristics, treatment patterns and prognostic factors in squamous cell bladder cancer. Clin Genitourin Cancer 16: e437-e442, 2018.

4. Arruda RP, Mariano MB, Pereira CF, Lima GC, Lessa TN and Neto MC: Laparoscopic cystoprostatectomy for bladder cancer in a male patient combined with open ileal conduit urinary diversion. Int Braz J Urol 43: 169-170, 2017.

5. Jiang K, Chen H, Tang K, Guan W, Zhou H, Guo X, Chen Z, Ye Z and Xu H: Puerarin inhibits bladder cancer cell proliferation through the mTOR/p70S6K signaling pathway. Oncol Lett 15: 167-174, 2018.

6. Wang PP, Zhu XF, Yang L, Liang H, Feng SW and Zhang RH: Puerarin stimulates osteoblasts differentiation and bone formation through estrogen receptor, p38 MAPK, and Wnt/ $\beta$-catenin pathways. J Asian Nat Prod Res 14: 897-905, 2012.

7. Guo XF, Yang ZR, Wang J, Lei XF, Lv XG and Dong WG: Synergistic antitumor effect of puerarin combined with 5-fluorouracil on gastric carcinoma. Mol Med Rep 11: 2562-2568, 2015.

8. Lin MH, Lee YH, Cheng HL, Chen HY, Jhuang FH and Chueh PJ: Capsaicin inhibits multiple bladder cancer cell phenotypes by inhibiting tumor-associated NADH oxidase (tNOX) and sirtuin1 (SIRT1). Molecules 21: 849, 2016.

9. Vaziri H, Dessain SK, Ng Eaton E, Imai SI, Frye RA, Pandita TK, Guarente L and Weinberg RA: hSIR2(SIRT1) functions as an NAD-dependent p53 deacetylase. Cell 107: 149-159, 2001.

10. Livak KJ and Schmittgen TD: Analysis of relative gene expression data using realtime quantitative PCR and the 2(Delta Delta C(T)) method. Methods 25: 402-408, 2001

11. Reulen RC, de Vogel S, Zhong W, Zhong Z, Xie LP, Hu Z, Deng Y, Yang K, Liang Y, Zeng X, et al: Physical activity and risk of prostate and bladder cancer in China: The South and East China case-control study on prostate and bladder cancer. PLoS One 12: e0178613, 2017.

12. Tang JL, Liu BY and Ma KW: Traditional Chinese medicine. Lancet 372: 1938-1940, 2008.

13. Chen T, Chen H, Wang Y and Zhang J: In vitro and in vivo antitumour activities of puerarin 6"-O-xyloside on human lung carcinoma A549 cell line via the induction of the mitochondria-mediated apoptosis pathway. Pharm Biol 54: 1793-1799, 2016.

14. Liu X, Zhao W, Wang W, Lin S and Yang L: Puerarin suppresses LPS-induced breast cancer cell migration, invasion and adhesion by blockage of NF- $\mathrm{KB}$ and Erk pathway. Biomed Pharmacother 92: 429-436, 2017.

15. $\mathrm{Yu} \mathrm{Z}$ and $\mathrm{Li} \mathrm{W}$ : Induction of apoptosis by puerarin in colon cancer HT-29 cells. Cancer Lett 238: 53-60, 2006.

16. Al-Qathama A, Gibbons S and Prieto JM: Differential modulation of $\mathrm{Bax} / \mathrm{Bcl}-2$ ratio and onset of caspase-3/7 activation induced by derivatives of justicidin B in human melanoma cells A375. Oncotarget 8: 95999-96012, 2017.

17. Zhang S, Qin F, Yang L, Xian J, Zou Q, Jin H, Wang L and Zhang L: Nucleophosmin mutations induce chemosensitivity in THP-1 leukemia cells by suppressing NF- $\mathrm{kB}$ activity and regulating Bax/Bcl-2 expression. J Cancer 7: 2270-2279, 2016.

18. Ruan L, Wang L, Wang X, He M and Yao X: SIRT1 contributes to neuroendocrine differentiation of prostate cancer. Oncotarget 9: 2002-2016, 2017

19. Kang YY, Sun FL, Zhang Y and Wang Z: SIRT1 acts as a potential tumor suppressor in oral squamous cell carcinoma. J Chin Med Assoc 81: 416-422, 2018.

20. Shuang T, Wang M, Zhou Y and Shi C: Over-expression of Sirt1 contributes to chemoresistance and indicates poor prognosis in serous epithelial ovarian cancer (EOC). Med Oncol 32: 260, 2015.

21. Zhang X, Chen J, Sun L and Xu Y: SIRT1 deacetylates KLF4 to activate Claudin-5 transcription in ovarian cancer cells. J Cell Biochem 119: 2418-2426, 2018.

22. Han L, Liang XH, Chen LX, Bao SM and Yan ZQ: SIRT1 is highly expressed in brain metastasis tissues of non-small cell lung cancer (NSCLC) and in positive regulation of NSCLC cell migration. Int J Clin Exp Pathol 6: 2357-2365, 2013.

This work is licensed under a Creative Commons Attribution-NonCommercial-NoDerivatives 4.0 International (CC BY-NC-ND 4.0) License. 